\title{
Hypoxia Induces an Undifferentiated Phenotype of Oral Keratinocytes in vitro
}

\author{
Hiroko Kato $^{a, b}$ Kenji Izumi $^{b}$ Atsushi Uenoyama ${ }^{c, d}$ Aki Shiomi ${ }^{c}$ \\ Shiuhyang Kuo ${ }^{a}$ Stephen E. Feinberg ${ }^{\mathrm{a}}$ \\ ${ }^{a}$ Department of Oral and Maxillofacial Surgery, University of Michigan, Ann Arbor, Mich., USA; Divisions of \\ ${ }^{b}$ Biomimetics, ${ }^{c}$ Oral Anatomy and ${ }^{\mathrm{d}}$ Oral and Maxillofacial Surgery, Niigata University Graduate School of Medical \\ and Dental Sciences, Niigata, Japan
}

\section{Key Words}

Oxygen tension · Oral keratinocyte $\cdot$ Cell cycle .

Differentiation $\cdot$ Microenvironment

\begin{abstract}
The aim of this study was to determine the effects of hypoxia on the proliferating potential and phenotype of primary human oral keratinocytes cultured at ambient oxygen tension (20\%) or at different levels of hypoxia ( 2 and $0.5 \% \mathrm{O}_{2}$ ). The effects of oxygen tensions on cellular metabolic activity, cell proliferation, clonogenicity and proliferation heterogeneity were measured. Cell cycle profiles were analyzed by a fluorescent-activated cell sorter, and $\mathrm{p} 21^{\mathrm{WAF} 1 / \mathrm{CIP} 1}$ expression in the $G_{0} / G_{1}$ phase was also concomitantly quantitated. The expression levels of cell cycle regulatory proteins were examined by immunoblotting, and the cellular senescence was assessed by senescence-associated $\beta$-galactosidase staining. Basal and suprabasal keratinocyte phenotypes were deter-

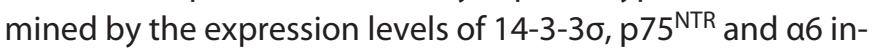
tegrin. Despite having a lower metabolism, the proliferation rate and clonogenic potential were remarkably enhanced in hypoxic cells. The significantly higher percentage of cells in the $G_{0} / G_{1}$ phase under hypoxia and the expression patterns of cell cycle regulatory proteins in hypoxic cells were indicative of a state of cell cycle arrest in hypoxia. Furthermore, a decrease in the expression of $\mathrm{p} 21^{\mathrm{WAF} 1 / \mathrm{CIP} 1}$ and $\mathrm{p} 16^{\mathrm{INK} 4 \mathrm{~A}}$ and fewer $\beta$-galactosidase-positive cells suggested a quiescent
\end{abstract}

\section{KARGER}

(C) 2015 S. Karger AG, Base

$1422-6405 / 15 / 1996-0393 \$ 39.50 / 0$

E-Mail karger@karger.com

www.karger.com/cto phenotype rather than a senescent one in hypoxic cells. Compared with normoxic cells, the differential expression patterns of keratinocyte phenotypic markers suggest that hypoxic cells that generate minimal reactive oxygen species, suppress the mammalian target of rapamycin activity and express hypoxia-inducible factor-1a favor a basal cell phenotype. Thus, regardless of the predisposition to the state of cell cycle arrest, hypoxic conditions can maintain oral keratinocytes in vitro in an undifferentiated and quiescent state.

(c) 2015 S. Karger AG, Base

\section{Abbreviations used in this paper}

CFSE

FACS

carboxyfluorescein diacetate succinimidyl ester

FITC

HIF-1a

mTOR

OD

PBS

p-S6

p-S6K

ROS

SA- $\beta-G a l$

$\mathrm{SD}$ fluorescence-activated cell sorting fluorescein isothiocyanate hypoxia-inducible factor- $1 \alpha$ mammalian target of rapamycin optical density phosphate-buffered saline phosphorylated-ribosomal S6 protein phosphorylated-ribosomal S6 protein kinase reactive oxygen species senescence-associated $\beta$-galactosidase standard deviation of the mean 


\section{Introduction}

In most mammalian tissues, the oxygen tension drops after it enters the lungs from $21 \%$ to less than $9 \%$ [Vanderkooi et al., 1991]. Oxygen is a potent biochemical signaling molecule that regulates the growth, fate and function of mammalian cells, including various stem cells, in terms of proliferation and differentiation [Haque et al., 2013]. In a natural niche, a specialized cellular microenvironment where stem cells reside, low oxygen tensions play a role in maintaining an undifferentiated stem cell phenotype [Mohyeldin et al., 2010]. At present, most in vitro culture conditions are employed under an ambient oxygen concentration of $21 \%$ in contrast to the $1-9 \%$ range in the niche [Mohyeldin et al., 2010]. In a variety of cells low oxygen tensions can provide beneficial effects for regenerative therapies because hypoxic conditions can promote cell proliferation in vitro [Santilli et al., 2010; Yamamoto et al., 2013].

An autologous tissue-engineered oral mucosa, constituting a full-thickness graft or an epithelial cell sheet, has been applied to patients intraorally and extraorally [Inatomi et al., 2006; Izumi et al., 2013]. Oral mucosal epithelium is highly active in terms of cell turnover and regeneration, which implicates the presence of an in situ stem cell population [Izumi et al., 2007]. Thus, oral mucosa keratinocytes can be an attractive stem cell source for regenerative medicine even though keratinocyte stem cells have not been specifically identified. However, an enriched population of oral keratinocyte progenitor/stem cells has been isolated [Izumi et al., 2007]. An important issue in tissue engineering/regenerative medicine is the expansion and maintenance of progenitor cells ex vivo to produce a large number of cells in an undifferentiated and proliferative state. The optimization of the expansion process leads to the maximization of cell yield, reducing cell cultivation time, the chance of contamination and total cost of the products.

Previous research has focused on hypoxia in pathological conditions, i.e. wound healing and cancer, and not with normal oral mucosa epithelium [Thorn et al., 1997; Chen et al., 2012]. Although, to date, there is no direct measurement of oxygen tension in vivo in oral epithelium, physiological oxygen tensions in oral mucosa appear to be low, as reported in skin [Carreau et al., 2011]. Since changes of cellular behavior and characteristics in oral keratinocytes under hypoxic conditions are poorly understood, it is not known whether $20 \%$ oxygen tension in vitro is an optimal environment to expand oral keratinocytes. Thus, the aim of this study is to demonstrate cellu- lar response and determine the changes in the proliferating potential and phenotypes of cultured oral keratinocytes under hypoxic conditions. The outcomes will provide a new strategy for the ex vivo manipulation of oral keratinocytes for use in regenerative medicine.

\section{Materials and Methods}

Primary Cell Culture under Hypoxic Conditions

Keratinized oral mucosa was obtained from patients undergoing minor dento-alveolar surgery at the Universities of Michigan and Niigata. The protocol for harvesting human oral mucosal tissue was approved by an internal review board of both institutes. All individuals signed informed consent before the tissue samples were procured. Primary human oral keratinocytes were isolated and cultured routinely in a 'complete' EpiLife ${ }^{\circledR}$ (Life Technologies, Carlsbad, Calif., USA) supplemented with EpiLife defined growth supplements (Life Technologies), $0.06 \mathrm{mM} \mathrm{Ca}^{2+}$, gentamicin (5.0 $\mu \mathrm{g} / \mathrm{ml}$; Life Technologies) and amphotericin B $(0.375 \mu \mathrm{g} / \mathrm{ml}$; Life Technologies) as described previously [Kato et al., 2013]. The majority of cells used in this study were from the 4 th to the 7 th passage, inclusive. To culture cells under hypoxic conditions, culture vessels were placed in a humidified molecular incubator chamber (Billups Rothenberg Inc., Del Mar, Calif., USA), flushed for 4 min with a gas mixture of $2 \% \mathrm{O}_{2}\left(5 \% \mathrm{CO}_{2}-93 \% \mathrm{~N}_{2}\right)$ and $0.5 \% \mathrm{O}_{2}(5 \%$ $\mathrm{CO}_{2}-94.5 \% \mathrm{~N}_{2}$ ), then placed in an incubator at $37^{\circ} \mathrm{C}$. Cells were fed with 2 and $0.5 \% \mathrm{O}_{2}$ tensions equilibrating complete media every other day. As a normoxic condition $\left(20 \% \mathrm{O}_{2}\right)$, vessels were placed in an incubator in ambient oxygen at $37^{\circ} \mathrm{C}$ in a humidified $5 \% \mathrm{CO}_{2}$ environment.

\section{Measurement of Cellular Metabolic Activity}

Oral keratinocytes $\left(5 \times 10^{3}\right)$ were plated into 96-well microplates (Costar, Corning, N.Y., USA) with $100 \mu$ l of complete EpiLife culture medium. Twenty-four hours later, after a medium change, cells were cultured in normoxic and hypoxic conditions for up to $96 \mathrm{~h}$. Cell Counting Kit-8 (Dojindo Molecular Technologies, Osaka, Japan) was used to determine cellular metabolic activity (dehydrogenase activity in viable cells) every $48 \mathrm{~h}$ according to the manufacturer's instructions. Optical density (OD) was measured at $450 \mathrm{~nm}$ with a reference wavelength of $690 \mathrm{~nm}$ using a Multiskan FC 96-well plate reader (Thermo Fisher Scientific, Waltham, Mass., USA). All assays were performed in triplicate. To eliminate variations among individual cells, we determined the ' $\%$ change of normoxic cells' (control) for comparison by dividing each OD of hypoxic cells by the OD of normoxic cells.

\section{Cell Proliferation}

To determine the cell proliferation, we counted the number of viable cells with Trypan blue (Sigma-Aldrich, St. Louis, Mo., USA). Cells were seeded into wells in a 6-well plate (Costar) at a density of $5 \times 10^{4}$ cells with $4 \mathrm{ml}$ of culture medium. Twenty-four hours later, the cells were placed in either normoxic or hypoxic conditions and fed every other day. The number of viable cells was counted every other day up to 6 days. The average cell number from 2 wells was calculated. To eliminate variations among individual cells, the '\% change of control' was determined. 
Clonogenic Assay

For colony-forming efficiency assay, $5 \times 10^{3}$ cells were plated into a 6-well plate (Costar) and cultured for 7 days under normoxic or hypoxic conditions with complete medium. Cells were fixed for 10 min with methanol and stained with $2 \%$ crystal violet (Baker Chemical, Phillipsburg, N.J., USA). We enumerated colonies consisting of sixteen cells or greater under the microscope. In addition, from the scanned image using Image J software (National Institutes of Health, Bethesda, Md., USA; http://imagej.nih.gov/ $\mathrm{ij} /$ ), the number of colonies larger than $1 \mathrm{~mm}$ in diameter was counted macroscopically. These counts were performed in triplicate. In order to eliminate variations among individual cells, the '\% change of control' was determined.

\section{Proliferation Tracking Assay}

To assess 'proliferative heterogeneity', we monitored the cycling activity based on the carboxyfluorescein diacetate, succinimidyl ester (CFSE) dye tracking as described elsewhere [Chadli et al., 2013]. In brief, cell suspension in $2 \%$ bovine serum albumin in a phosphate-buffered saline (PBS) at a density of $10^{6}$ cells $/ \mathrm{ml}$ was incubated in a final concentration of $10 \mu \mathrm{M}$ CFSE (CellTrace ${ }^{\mathrm{TM}}$ CFSE Cell Proliferation Kit, C34554; Life Technologies, Eugene, Oreg., USA) solution in the dark for $20 \mathrm{~min}$ at $37^{\circ} \mathrm{C}$, left for another $30 \mathrm{~min}$ at room temperature, and the labeling was ceased by adding prewarmed complete EpiLife culture medium. After a minor subset of cells was separated, the majority of cells were plated for subsequent culture. The CFSE dye profile was analyzed by fluorescence-activated cell sorting (FACS) Aria II (BD Biosciences, San Jose, Calif., USA) for cells immediately after the labeling, and was cultured for 48 and 72 h. 7-Aminoactinomycin D (BD Biosciences) and Fluoresbrite ${ }^{\circledR}$ microspheres (PolyScience Inc., Warrington, Pa., USA) were used for the elimination of nonviable cells and a fluorescein isothiocyanate (FITC) standard, respectively. To compare the proliferative heterogeneity, standard deviations and median values were calculated. FlowJo software (FLOWJO, LCC, Ashland, Oreg., USA) was used to illustrate the CFSE dye profile.

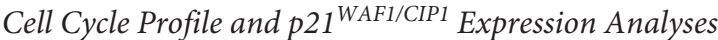

The cell cycle and the expression level of $\mathrm{p} 21^{\mathrm{WAF} 1 / \mathrm{CIP} 1}$ were examined by biparameter flow cytometry. Cells grown in a $100-\mathrm{mm}$ dish (Falcon, Big Flats, N.Y., USA) under normoxic and hypoxic conditions for $48-72 \mathrm{~h}$ were collected and fixed in a final concentration of $80 \%$ ice-cold methanol at $4{ }^{\circ} \mathrm{C}$ for at least $24 \mathrm{~h}$. After washing $5 \times 10^{5}$ fixed cells with $2 \%$ bovine serum albumin in PBS, the cells were immunostained with $1 / 200 \mu$ l of Alexa Fluor 488 -conjugated anti-p21 WAF1/CIP1 antibody (No. 5487; Cell Signaling Technology, Beverly, Mass., USA) for $1 \mathrm{~h}$ at room temperature in the dark. Subsequently, cells were incubated with propidium iodide $(10 \mu \mathrm{g} / \mathrm{ml}$; Sigma-Aldrich) and ribonuclease A (100 $\mu \mathrm{g} / \mathrm{ml}$; SigmaAldrich) in PBS for $30 \mathrm{~min}$ at $37^{\circ} \mathrm{C}$. After being kept on ice for 15 $\mathrm{min}$, the samples were analyzed by FACS Aria II (BD Biosciences). Simultaneously, the expression level of p21 2 WAF1/CIP1 in the $G_{0} / G_{1}$ phase fraction gated by R1 was also monitored, based on Alexa Fluor 488-conjugated rabbit IgG isotype control (No. 4340; Cell Signaling Technology). Modfit software (BD Biosciences) was used to determine the cell cycle profile.

\section{Immunoblotting}

RIPA buffer was used to obtain whole-cell extracts. A 10- to 15$\mu \mathrm{g}$ protein per lane was resolved by SDS-PAGE and electrophoretically transferred to polyvinylidene difluoride membranes. Mem- branes were then incubated overnight at $4^{\circ} \mathrm{C}$ with 1:2,000 anti-cyclin D1 and pRb (No. 2926 and No. 9307; Cell Signaling Technology), 1:1,000 anti-Rb (No. 9309; Cell Signaling Technology), 1:1,000 anti-Rb2/p130 (610262; BD Biosciences), 1:500 antip16 ${ }^{\mathrm{INK} 4 \mathrm{~A}}$ and $\mathrm{p} 75^{\mathrm{NGF}}$ (ab81278 and ab52987; Abcam, Cambridge,

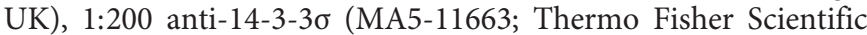
Pierce, Rockford, Ill., USA), 1:1,000 anti-hypoxia-inducible factor1a (HIF-1 $\alpha$; NB100-479; Novus Biologicals, Littleton, Colo., USA), 1:1,000 anti-phosphorylated-ribosomal S6 protein kinase (p-S6K; No. 9234; Cell Signaling Technology), 1:1,000 anti-S6K (No. 2708; Cell Signaling Technology), 1:1,000 anti-phosphorylated-ribosomal S6 protein (p-S6; No. 4857; Cell Signaling Technology), 1:1,000 anti-S6 (No. 2217; Cell Signaling Technology) or 1:2,500 $\beta$-actin (No. 4970; Cell Signaling Technology), followed by 1:2,500 goat antimouse or anti-rabbit (No. 7076 and No. 7074; Cell Signaling Technology). Signals were detected by the chemiluminescence reagent (Cell Signaling Technology). For the quantitative comparison of protein bands, films were scanned and quantified with Image J software. The ratio of phosphorylated to total $\mathrm{Rb}$ protein was calculated from three independent immunoblots.

\section{Senescence-Associated $\beta$-Galactosidase Staining}

Cells were plated into wells in a 6-microwell plate at a density of $1 \times 10^{5}$ cells with $2 \mathrm{ml}$ of culture medium, and cultured under normoxic or hypoxic conditions for $72 \mathrm{~h}$. Senescence-associated $\beta$-galactosidase (SA- $\beta$-Gal) staining activity was detected using the SA- $\beta$-Gal staining kit (No. 9860; Cell Signaling Technology) according to the manufacturer's instructions. After six fields were randomly photographed under the microscope $(200 \times)$, the $\beta-G a l-$ positive cells were counted and the percentage was calculated by dividing the number by the total cell count and multiplying by 100 .

\section{Detection of Reactive Oxygen Species}

Reactive oxygen species (ROS) were detected by Total ROS/ Superoxide Detection Kit (ENZ-51010; ENZO Life Sciences, Farmingdale, N.Y., USA) according to the manufacturer's instructions. Oral keratinocytes $\left(5 \times 10^{3}\right)$ seeded in 96-well black wall/ clear bottom plates (Falcon) were cultured under normoxic and hypoxic conditions for $72 \mathrm{~h}$. For a positive control, cells were treated with the ROS inducer pyocyanin $(200 \mu \mathrm{M})$ at $37^{\circ} \mathrm{C}$ for $30 \mathrm{~min}$. Subsequently, the cells were washed with $200 \mu \mathrm{l}$ of $1 \times$ wash buffer and loaded with $100 \mu \mathrm{l}$ of ROS/superoxide detection reagents. The fluorescent intensity was measured 45 min after loading using a microplate fluorometer (TriStar LB 941; Berthold Technologies GmbH \& Co. KG, Bad Wildbad, Germany) with excitation at 490 $\mathrm{nm}$ and emission at $525 \mathrm{~nm}$ for the detection. All assays were performed in sextuplicate.

\section{Analysis of $\alpha 6$ Integrin Expression}

The expression level of $a 6$ integrin cultured in hypoxia and normoxia for a 72-hour period was quantified by FACS Aria II (Beckton Dickinson). After the cells were harvested they were fixed with $4 \%$ paraformaldehyde for $10 \mathrm{~min}$, followed by permeabilization in $0.5 \%$ Triton-X-100 for $10 \mathrm{~min}$ at room temperature. After washing with PBS, the cells were incubated with a 1:200 dilution of FITCconjugated anti- $\alpha 6$ integrin antibody (clone GOH3, sc-19622; Santa Cruz Biotechnology, Santa Cruz, Calif., USA) for $1 \mathrm{~h}$ at room temperature. The expression level of a 6 integrin between cells cultured in hypoxia and normoxia was quantified by FACS Aria II (Becton Dickinson). FITC-conjugated, isotype-matched, normal rat $\mathrm{IgG}_{1}$ was used as the negative control (BD Biosciences). 


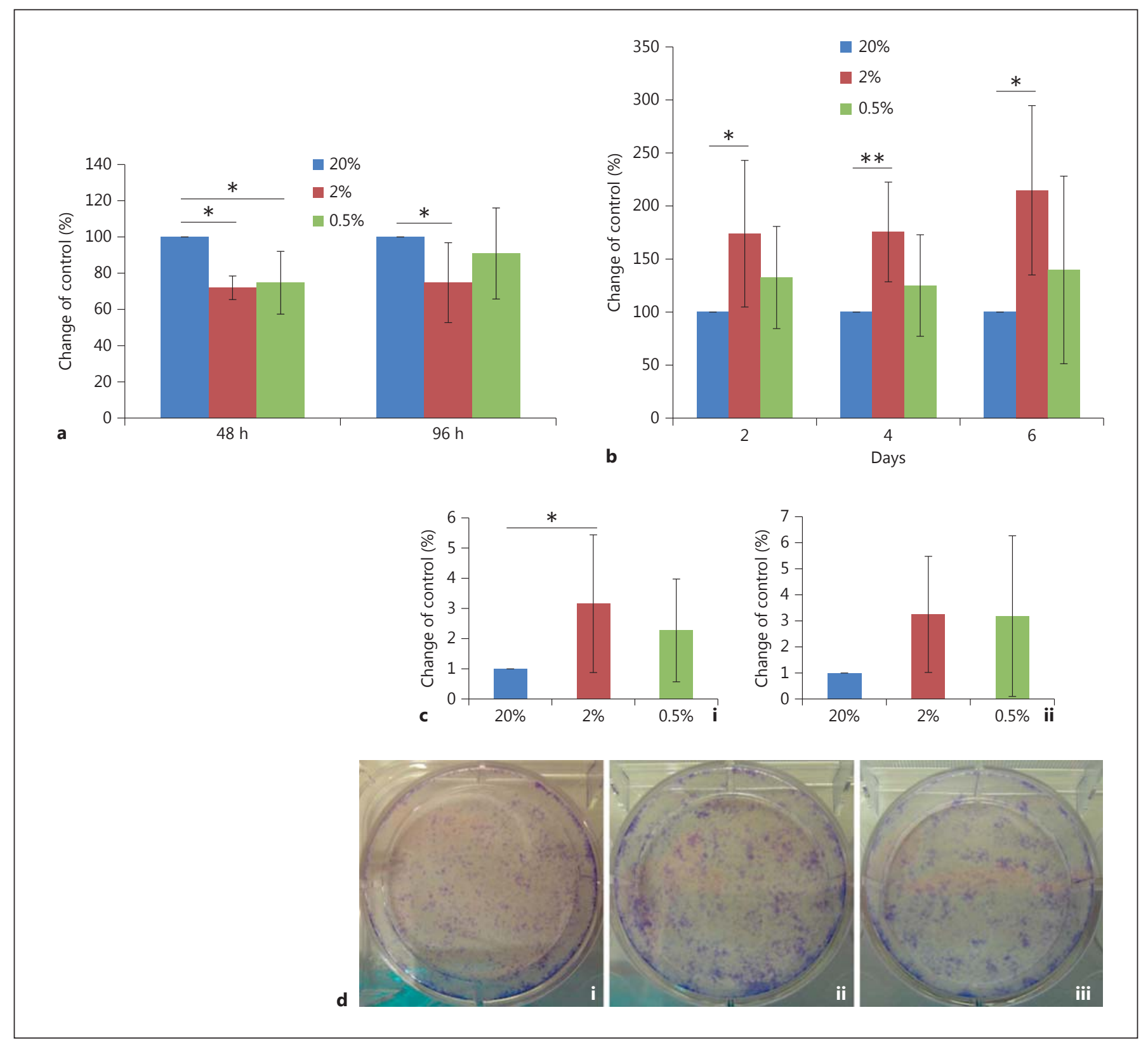

Fig. 1. a Effects of three different oxygen tensions (20, 2 and 0.5\%) on the cellular metabolic activity of human oral keratinocytes up to $96 \mathrm{~h}$. The metabolic activity was assessed using Cell Counting Kit-8 (Dojindo Molecular Technologies; $n=10$ ). Assays were performed in triplicate. Asterisks represent statistically significant differences determined by the Steel-Dwass test $(* p<0.05)$. b Effects of three different oxygen tensions on the proliferation rate of human oral keratinocytes up to 6 days. Viable cells were stained with Trypan blue and counted $(n=8)$. Assays were performed in duplicate. Asterisks represent statistically significant differences determined by Tukey's post hoc test $\left(* \mathrm{p}<0.05{ }^{* *} \mathrm{p}<0.01\right)$. c Effects of three different oxygen tensions on the colony-forming efficien- cy of human oral keratinocytes. Cells were stained with crystal violet and the number of colonies were microscopically (i) and macroscopically (ii) counted $(n=9)$, as stated in Materials and Methods. An asterisk represents a statistically significant difference as determined by Tukey's post hoc test $\left({ }^{*} \mathrm{p}<0.05\right)$. The statistical differences between normoxic and hypoxic cells were marginal except for the microscopic quantification between the 2 and $20 \% \mathrm{O}_{2}$ culture conditions. d Representative images of clonogenic assay. After cells were cultured for 4 days at $20 \% \mathrm{O}_{2}$ (i), $2 \% \mathrm{O}_{2}$ (ii) and $0.5 \% \mathrm{O}_{2}$ (iii), colonies were fixed and stained with crystal violet as aforementioned. 


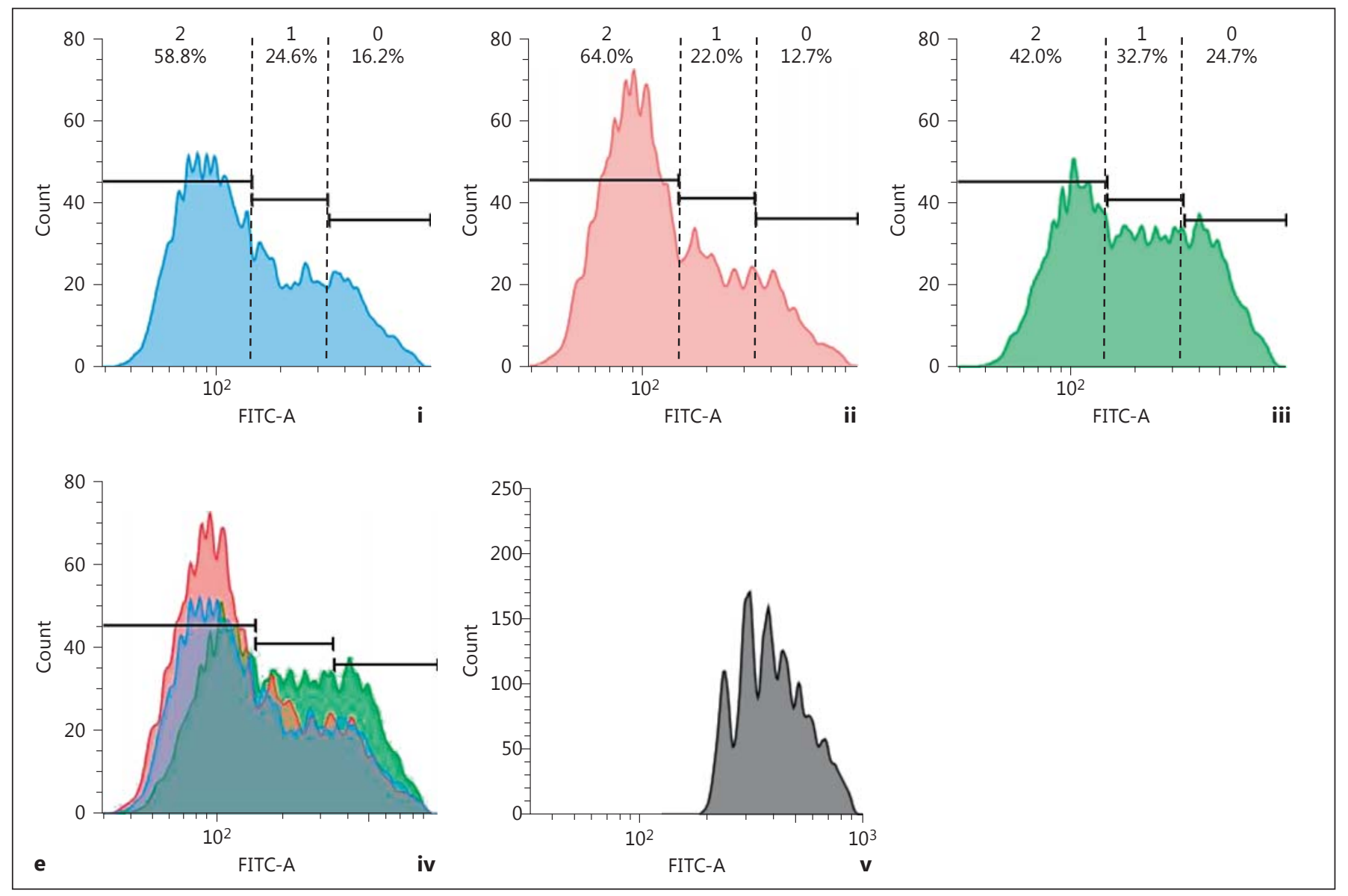

Fig. 1. e CFSE dye profiles of cells cultured in normoxic and hypoxic conditions for $48 \mathrm{~h}$. Their patterns were diverse among different oxygen tensions as well as individuals: $20 \% \mathrm{O}_{2}$ (i), $2 \% \mathrm{O}_{2}$ (ii), $0.5 \% \mathrm{O}_{2}$ (iii), overlay (iv) and FITC standard beads (v). The data shown are representative of six separate experiments. The values shown in $\mathbf{i}$-iii are the number of division and the percentage of cells for each division according to the protocol of Chadli et al. [2013].

\section{Immunocytochemistry/Fluorescence}

Oral keratinocytes grown in chamber slides (Thermo Fisher Scientific), around $70 \%$ confluent, were cultured under hypoxic conditions for $72 \mathrm{~h}$ before they were fixed with $4 \%$ paraformaldehyde for $20 \mathrm{~min}$. They were then permeabilized with $0.3 \%$ Triton X-100 for 10 min, rinsed several times with PBS, incubated with $10 \%$ normal goat serum for $60 \mathrm{~min}$ at room temperature, then incubated with primary antibody to HIF-1a (NB100-479, 1:100) overnight at $4{ }^{\circ} \mathrm{C}$. Alexa Fluor 594-conjugated goat anti-rabbit IgG (Life Technologies) was applied for $90 \mathrm{~min}$ at room temperature. After removing the chamber, glass coverslips were mounted onto slides in Vectashield (Vector Lab, Vector Lab, Burlingame, Calif., USA) for DNA staining.

\section{Statistical Analysis}

The results are presented as the mean \pm standard deviation of the mean (SD) of the values obtained. Comparisons among three different $\mathrm{O}_{2}$ tensions were analyzed by either the Tukey-Kramer or SteelDwass test after determining whether the samples were normally distributed or not. A p value $<0.05$ was considered statistically significant.

\section{Results}

\section{Cellular Metabolic Activity, Cell Proliferation, \\ Clonogenic and Proliferation Tracking Assays}

The cellular metabolic activity of hypoxic cells cultured for $48 \mathrm{~h}$ was significantly lower than seen in normoxic cells, while it was statistically different only between cells cultured for $96 \mathrm{~h}$ at 20 and $2 \% \mathrm{O}_{2}$ (fig. 1a). No statistical difference was noted between cells cultured at 2 and $0.5 \% \mathrm{O}_{2}$. We counted the number of viable cells in culture to assess the proliferation rate of cells under hypoxia. Cell proliferation was found to be significantly higher at both 2 and $0.5 \% \mathrm{O}_{2}$ compared with $20 \% \mathrm{O}_{2}$ (fig. 1b). The proliferation potential of hypoxic cells was also assessed by clonogenic assay. The number of colonies yielded under hypoxia was 2-3 

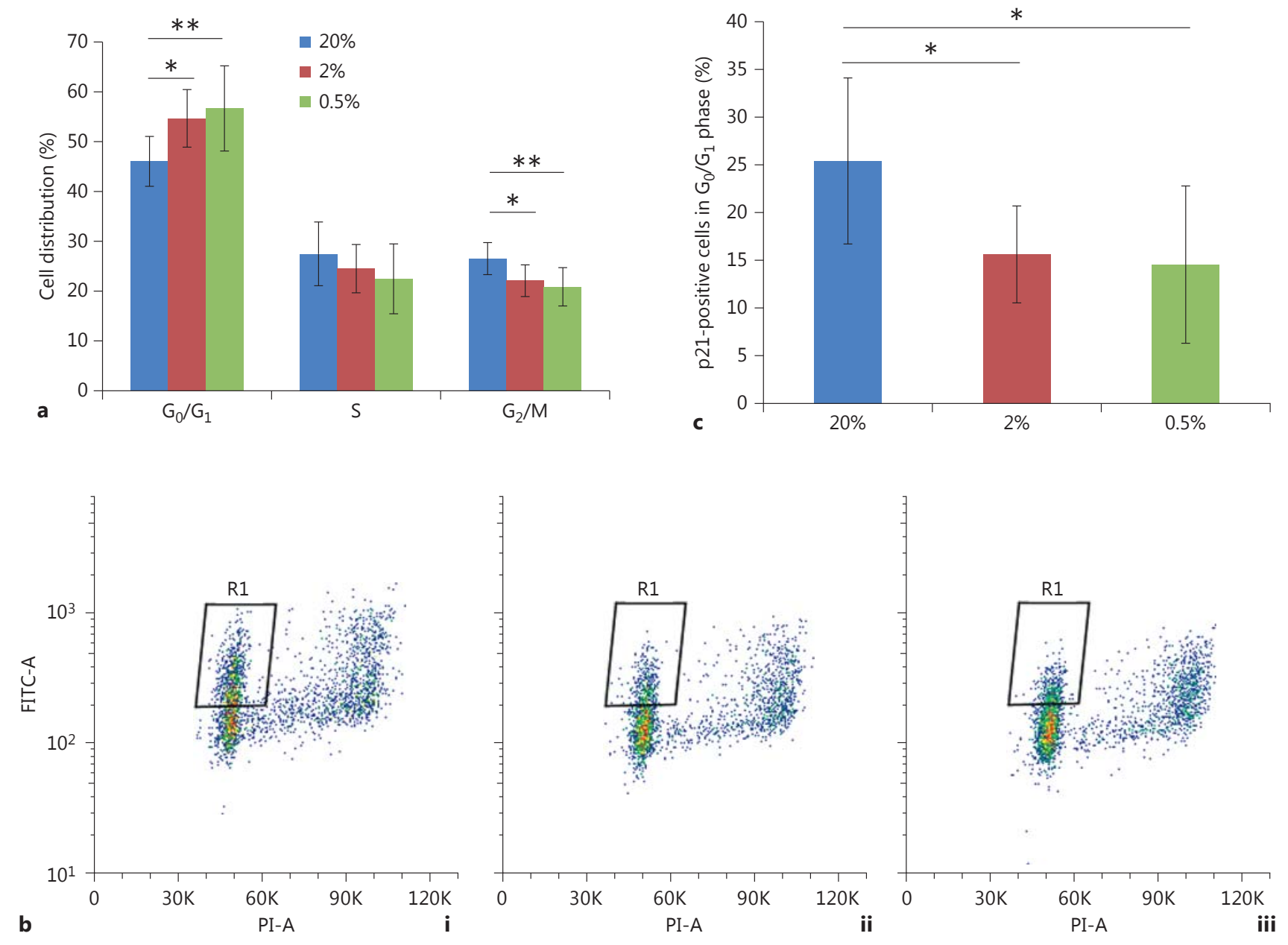

Fig. 2. a Distribution of human oral keratinocytes cultured at three different oxygen tensions (20,2 and $0.5 \%)$ in various phases of the cell cycle. The bar chart shows the cell distribution (\%) in the $\mathrm{G}_{0} /$ $\mathrm{G}_{1}, \mathrm{~S}$ and $\mathrm{G}_{2} / \mathrm{M}$ phases as determined by ModFit software. Data are the mean percentage \pm SD of 11 independent experiments. Asterisks represent statistically significant differences as determined by Tukey's post hoc test $\left({ }^{*} \mathrm{p}<0.05 ;{ }^{* *} \mathrm{p}<0.01\right)$. b Representative

dot plot images of flow cytometric analysis of DNA content and p2 $1^{\mathrm{WAF} / / \mathrm{CIP} 1}$ expression: $20 \% \mathrm{O}_{2}$ (i), $2 \% \mathrm{O}_{2}$ (ii) and $0.5 \% \mathrm{O}_{2}$ (iii). c Ratio of p21 $1^{\text {WAF1/CIP1 }}$-positive cells within the $\mathrm{G}_{0} / \mathrm{G}_{1}$ phase of normoxic and hypoxic oral keratinocytes $(n=12)$. Statistically significant differences were present between normoxic and hypoxic cells, as determined by Tukey's post hoc test $\left({ }^{*} \mathrm{p}<0.05\right)$.

times higher than normoxia by both microscopic and macroscopic quantification (fig. 1c, d). Furthermore, we examined the cycle of division in normoxic and hypoxic cells by using the CFSE dye tracking assay, and detected a variety of patterns of the CFSE profiles among different oxygen tensions (fig. 1e), while the statistical analysis of the SD and median values in CFSE profiles did not show significant differences $(\mathrm{p}=$ $0.15)$.

\section{Cell Cycle Profile and Cell Cycle Regulatory Protein Expression}

We analyzed the cell cycle profile to explain the dichotomy between a lower metabolism and higher proliferation of the cultured cells. The proportions of actively cycling (in the $\mathrm{G}_{2} / \mathrm{M}$ phase) and DNA-replicating (in the $S$ phase) cells were fewer in hypoxic cells than in the normoxic cells, consistent with the noted predominance of cells in the $G_{0} / G_{1}$ phase, implying a state of cell cycle arrest occurred more readily under hypoxic conditions 
(fig. 2a). To distinguish quiescence from senescence within the $G_{0} / G_{1}$ phase of the cell subpopulation, p21 WAF1/CIP1 expression, which is required for initiating an irreversible growth arrest, was concurrently measured by flow cytometry (fig. 2b) [Topley et al., 1999]. The proportion of cells that expressed $\mathrm{p} 21^{\mathrm{WAF} 1 / \mathrm{CIP} 1}$ in the subpopulation of the $\mathrm{G}_{0} / \mathrm{G}_{1}$ phase in hypoxic conditions was significantly lower than that in normoxic condition (fig. 2c). An immunoblot of cyclin D1 expression and phosphorylated-Rb protein, which is involved in regulating cell cycle progression from the $G_{1}$ to $S$ phase, was suppressed in hypoxic conditions (fig. 3a). Densitometry reading confirmed that the ratio of phosphorylated to total $\mathrm{Rb}$ protein was statistically different between normoxic cells and hypoxic cells (fig. 3b). The expression of $\mathrm{p} 16^{\mathrm{INK} 4 \mathrm{~A}}$ was also reduced in hypoxic conditions consistent with the downregulation of $\mathrm{p} 21^{\mathrm{WAF} 1 / \mathrm{CIP} 1}$ (fig. 3a). In contrast, the higher expression level of $\mathrm{Rb} 2 / \mathrm{p} 130$, a marker of cells in the $\mathrm{G}_{0}$ phase, was seen at $0.5 \%$ oxygen tension (fig. $3 \mathrm{a}$ ). To further determine if the state of cell cycle arrest induced by hypoxia was reversible or irreversible, we assessed SA$\beta$-Gal activity and found that the number of SA- $\beta$-Galpositive cells was higher under normoxia than hypoxia (fig. 4a, b). This also supported the effects of hypoxic conditions maintaining oral keratinocytes in a quiescent (reversible cell cycle arrest) state rather than entering into a state of senescence (irreversible cell cycle arrest).

\section{Oral Keratinocytes Favor an Undifferentiated \\ Phenotype under Hypoxia}

We also assessed whether the cell cycle changes noted in hypoxic conditions had an impact on the status of un-

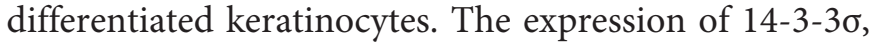
a regulatory protein specific to suprabasal differentiated keratinocytes, was inhibited in hypoxic cells (fig. 5a). Cells cultured at $0.5 \%$ oxygen tension had a higher expression of $\mathrm{p} 75^{\mathrm{NTR}}$, a putative stem cell marker for keratinocytes [Nakamura et al., 2007], when compared to cells cultured at either 2 or $20 \%$ oxygen (fig. $5 \mathrm{a}$ ). The ratio of a6 integrin-immunopositive cells, similar in size to the documented smaller stem cells [Izumi et al., 2009], was significantly higher in the $0.5 \%$ oxygen condition than in normoxia (fig. 5b). In addition, we further analyzed the levels of intracellular ROS and mammalian target of rapamycin (mTOR) activity via downstream substrates because both are important modulators of energy metabolism for the maintenance of quiescent cells. As a consequence, hypoxic conditions significantly inhibited both total ROS production and mTOR activity in oral keratinocytes compared with normoxic cells (fig. $5 c$, d).

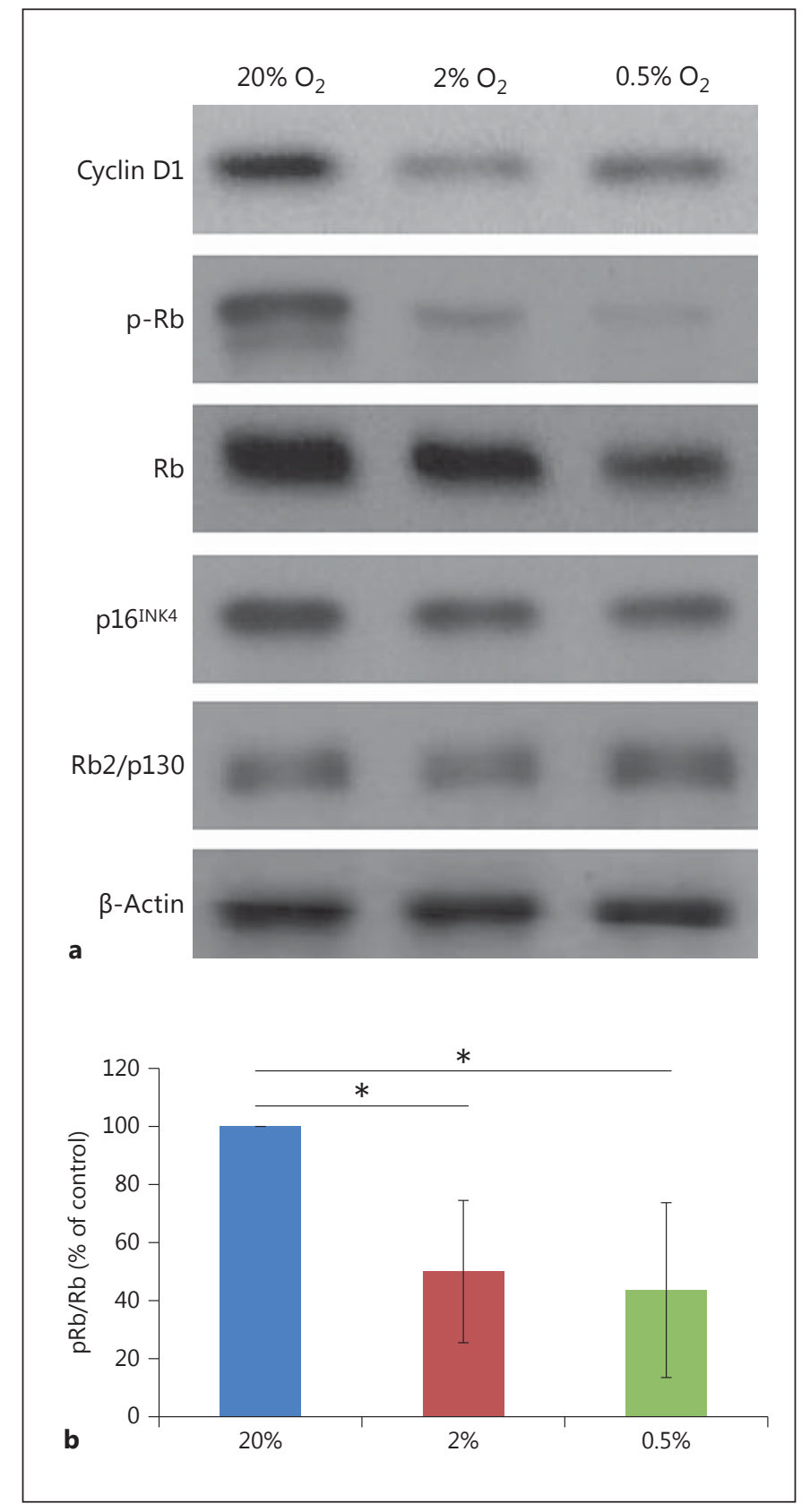

Fig. 3. a Expression of cell cycle regulatory proteins. Western immunoblotting detection of cyclin D1, phospho-Rb, Rb, $\mathrm{p} 16^{\mathrm{INK} 4}$ and $\mathrm{Rb} 2 / \mathrm{p} 130$ in oral keratinocytes cultured in three different oxygen tensions for $48 \mathrm{~h}$. The results shown are representative of 4 separate experiments; $\beta$-actin is shown as a loading control. $\mathbf{b} \mathrm{Rb}$ phosphorylation of cells cultured in normoxic and hypoxic conditions was quantified based on the densitometric analysis $(n=3)$. A statistically significant difference of the ratio of phosphorylated to total $\mathrm{Rb}$ protein was present between normoxic and hypoxic cells, as determined by Tukey's post hoc test $(* \mathrm{p}<0.05)$. 
Fig. 4. a Ratio of positive cells stained with SA- $\beta$-Gal at $\mathrm{pH} 6$ under normoxia and hypoxia $(n=6)$. There was a statistically significant difference between the 2 and $20 \% \mathrm{O}_{2}$ culture condition, although the difference between the 0.5 and $20 \% \mathrm{O}_{2}$ pressure was marginal, which was determined by Tukey's post hoc test $(* \mathrm{p}<0.05)$. b Representative images of SA- $\beta$-Gal staining after cells were cultured for $72 \mathrm{~h}$ at $20 \% \mathrm{O}_{2}(\mathbf{i}), 2 \% \mathrm{O}_{2}$ (ii) and $0.5 \% \mathrm{O}_{2}$ (iii). Scale bars $=100$ $\mu \mathrm{m}$.

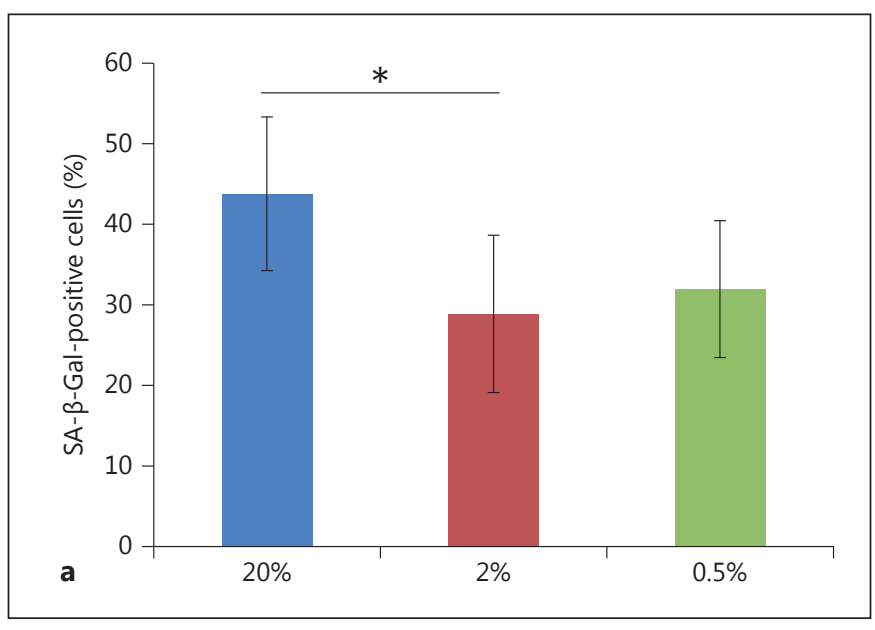

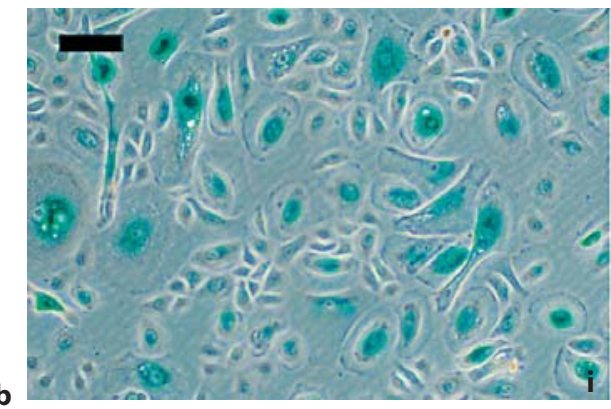

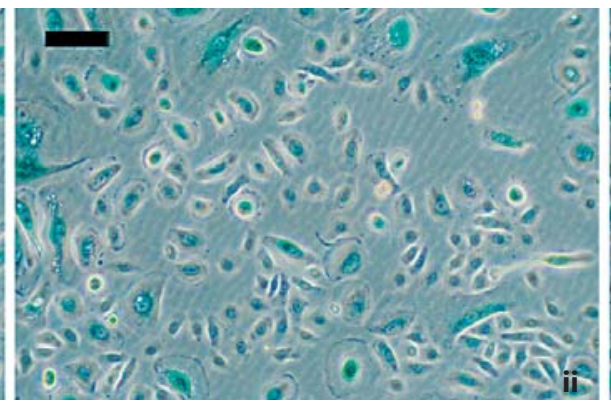

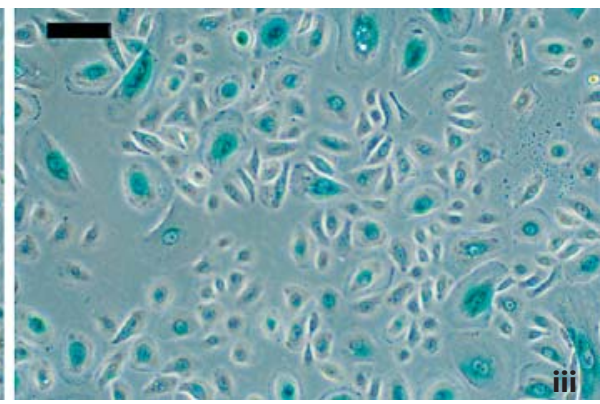

\section{HIF-1 $\alpha$ Expression in Hypoxic Cells}

These results would seem to indicate that hypoxia favors a basal stem-like cell phenotype in oral keratinocytes and is consistent with the cells being in a more undifferentiated state. Finally, we confirmed the induction of HIF-1 $\alpha$, a transcription factor identified as the master regulator for cellular adaptation to hypoxia, noted under hypoxic conditions (fig. 6a, b). This implies that low oxygen tensions mediate the cellular responses.

\section{Discussion}

The present study demonstrates the effects of 2 and $0.5 \% \mathrm{O}_{2}$ tensions on the cellular responses of primary human oral keratinocytes in vitro. One of the characteristic changes of oral keratinocytes under hypoxia is the enhancement of the cell proliferation and clonogenicity. The enhanced clonogenicity induced by the hypoxic condition between 1 and $5 \% \mathrm{O}_{2}$ has been seen not only in epithelial cells, skin and corneal limbus [Ngo et al., 2007; Bath et al., 2013], but also mesenchymal stem cells [Grayson et al., 2007; Yamamoto et al., 2013]. Thus, this cell behavior is consistent with the results seen in our study. However, the observed lower metabolism would appear to be in conflict with the higher proliferation rates seen in hypoxic cells. Several studies have reported that mesenchymal stem cells can be maintained in an undifferentiated state and expanded under hypoxic conditions by enhancing glycolysis instead of mitochondrial oxidative phosphorylation. This implies that metabolic downregulation of oral keratinocytes cultured in hypoxic conditions is not directly related to a higher proliferation rate, especially under $2 \%$ oxygen tension in this study [Deschepper et al., 2011; Buravkova et al., 2013]. This adaptive metabolic switch can result in an increase in ATP generation, which is a critical factor in increasing cell survival at low oxygen levels [Kim et al., 2014].

In this study, the cell cycle profile revealed the low oxygen tensions predisposed to induce cell cycle arrest, apparently in the $G_{0} / G_{1}$ phase, which was also confirmed by the expression pattern of regulatory cell cycle proteins, cyclin D1, Rb, phospho-Rb, Rb2/p130 and p16 ${ }^{\text {INK4A }}$ [Genovese et al., 2006; Wen et al., 2010; Helmbold et al., 2012; Chandler and Peters, 2013]. Hypoxia-induced cell 


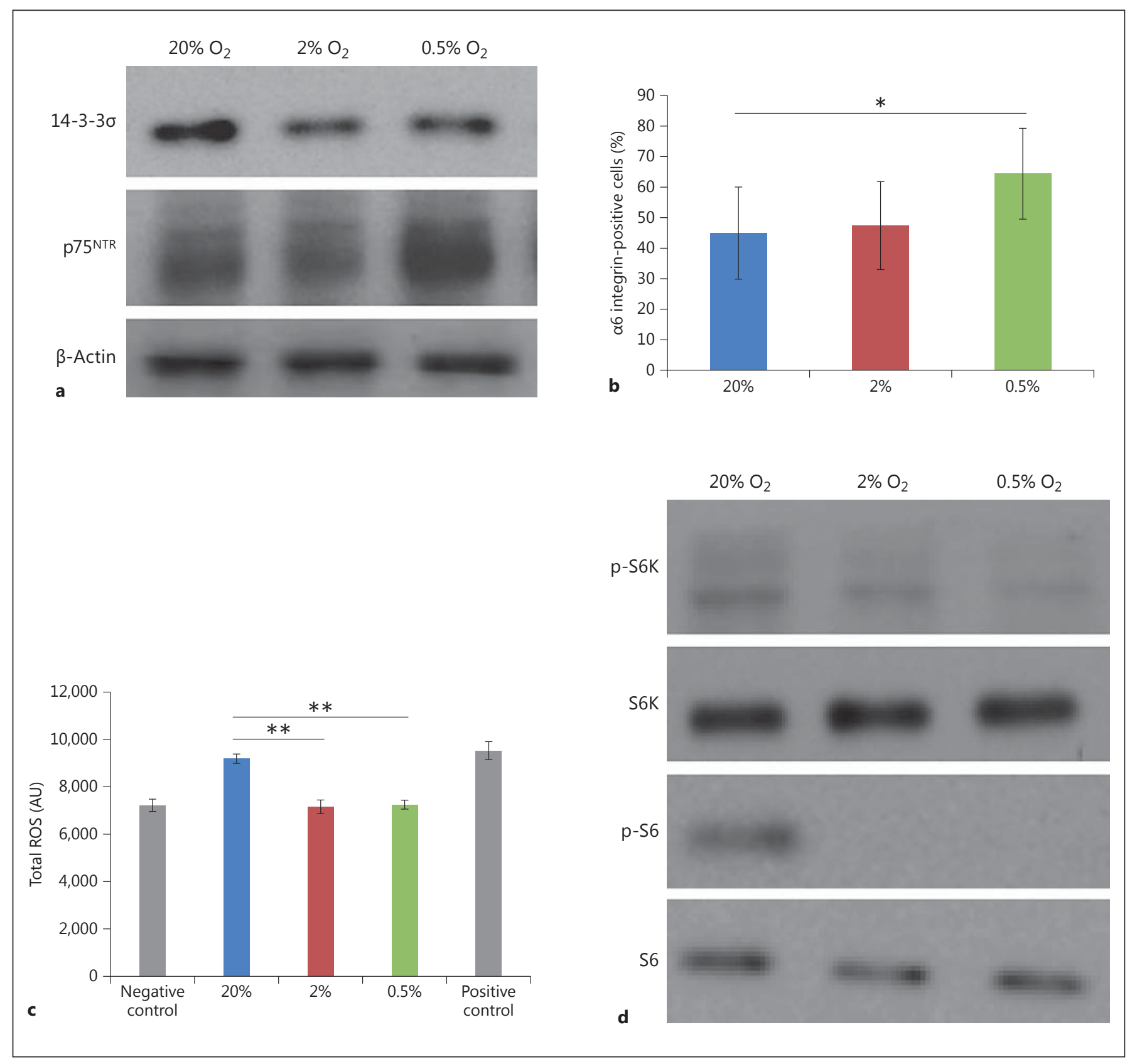

Fig. 5. a Expression of basal and suprabasal keratinocyte phenotypic markers. Western immunoblotting detection of 14-3-3 $\sigma$ and p $75^{\text {NTR }}$ in oral keratinocytes cultured in three different oxygen tensions for $48 \mathrm{~h}$. The results shown are representative of 4 separate experiments; $\beta$-actin is shown as a loading control. $\mathbf{b}$ Ratio of a6 integrin-positive cells under normoxia and hypoxia detected by flow cytometric analysis $(n=9)$. The a6 integrin expression ratio significantly increased at the oxygen tension of $0.5 \%$ compared with $20 \% \mathrm{O}_{2}$ pressure, while there was no statistical difference between the 2 and $20 \% \mathrm{O}_{2}$ culture condition, as determined by Tukey's post hoc test $\left({ }^{*} \mathrm{p}<0.05\right)$. c Total ROS production levels under nor- moxia and hypoxia measured by a microplate fluorometer $(n=10)$. Cells cultured at $20 \% \mathrm{O}_{2}$ pressure generated total ROS and their levels were close to those of positive control cells incubated with $200 \mu \mathrm{M}$ of pyocyanin. In contrast, total ROS was barely detected in cells cultured in hypoxic conditions. There was a remarkable statistical difference between normoxic and hypoxic culture conditions, as determined by Tukey's post hoc test $\left({ }^{*} \mathrm{p}<0.01\right)$. d Expression of downstream substrates of the mTOR signaling pathway. Western immunoblotting detection of p-S6K, S6K, p-S6 and S6 in oral keratinocytes cultured in three different oxygen tensions for $48 \mathrm{~h}$. The results shown are representative of 3 separate experiments. 

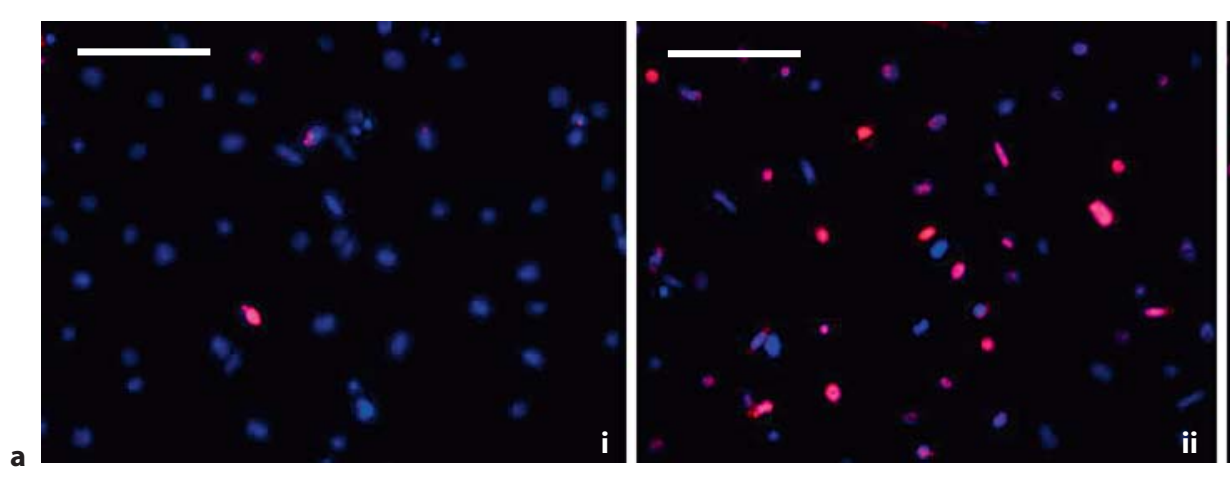

ii

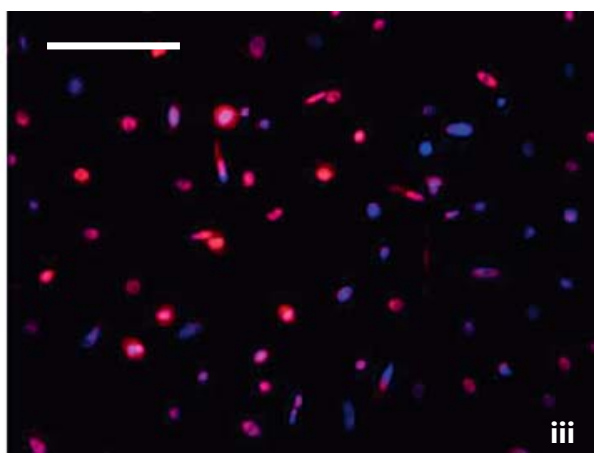

(⿸丆口

Fig. 6. a Immunofluorescence staining showed that only a few cells expressed HIF-1 $\alpha$ in their nuclei in normoxic conditions. In contrast, a large number cells expressed HIF-1 $\alpha$ in their nuclei under 2 and $0.5 \% \mathrm{O}_{2}$ tensions: $20 \% \mathrm{O}_{2}$ (i), $2 \% \mathrm{O}_{2}$ (ii) and $0.5 \% \mathrm{O}_{2}$ (iii). Original magnification $\times 200$. Scale bar $=100 \mu \mathrm{m}$. b Higher expression of HIF-1 $a$ was detected from the whole-cell lysates cultured in hypoxic conditions; $\beta$-actin is shown as a loading control.

cycle arrest that was concurrent with the higher cell proliferation and clonogenicity presented in this study is viewed as contradictory, as also previously seen in a study with limbal epithelial cells [Miyashita et al., 2007]. However, this finding is supported by a recent study showing that cycling and a quiescent cell cycle state can coexist within an isogenic cell population [Overton et al., 2014]. Another experimental work elucidating the balance between cell cycle arrest and cell proliferation by using a bistable switch model and a bifurcation diagram indicated that there is a certain range of the levels in external signals, such as growth factors, extracellular matrix and cell density, allowing a state of cell cycle arrest to coexist with cell proliferation [Gérard and Goldbeter, 2014]. Thus, a higher cell density resulting from an increase in the proliferation rate under hypoxia might impinge on our results.

The present study also showed a decrease in the expression level of $\mathrm{p} 21^{\mathrm{WAF} 1 / \mathrm{CIP} 1}$ and lower SA- $\beta-$ Gal activity, indicating that this growth arrest is not an irreversible senescence but a reversible quiescence, and the subset of cells not expressing p21 WAF1/CIP1 may be capable of contributing to the cell proliferation [Weinberg et al., 2002; Jung et al., 2010; Cheung and Rando,
2013]. Since quiescent cells were recently thought to be distinct from cycling cells or cell cycle arrested cells, we speculate that the phenotype seen in hypoxic cell subsets is mainly quiescence showing a state of cell cycle arrest that enables cells to reenter a proliferating state after transient arrest [Yao, 2014]. This is supported by the studies on suppression of conversion from arrest to senescence by hypoxia [Leontieva et al., 2012; Blagosklonny, 2013]. Moreover, the tendency of diverse patterns of CFSE dye profile under different oxygen tensions could also denote the heterogeneous quiescent states, leading to heterogeneous proliferation [Yao, 2014]. tiated state was the other major hallmark in this study, confirmed by the expression pattern of the suprabasal layer-specific differentiated keratinocyte phenotypic

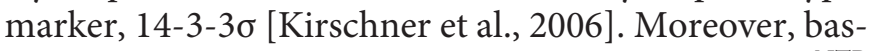
al cell phenotypic markers such as $a 6$ integrin and $\mathrm{p} 75^{\mathrm{NTR}}$ [Nakamura et al., 2007; Rezvani et al., 2011b] were noted to be expressed in cells under $0.5 \%$ oxygen pressure. This was in agreement with previous studies on skin keratinocytes [Ngo et al., 2007; Rezvani et al., 2011b] as well as other epithelial cells [O'Callaghan et al., 2011; Vaapil et
The ability of hypoxic cells to maintain an undifferen- 
al., 2012]. Taken together, these outcomes illustrate that hypoxia can maintain oral keratinocytes in an undifferentiated state. Thus, a low oxygen microenvironment in vivo may act as a reservoir for a 'progenitor' subset of the basal cell layer in stratified epithelium [Nakamura et al., 2007]. In addition, cells cultured in $0.5 \% \mathrm{O}_{2}$ pressure may behave differently from cells in $2 \% \mathrm{O}_{2}$ pressure based on the differential expression pattern of those three markers. Our results show that oral keratinocytes cultured in hypoxic conditions exist in a quiescent and undifferentiated state, preventing the cells from moving into a senescent state and preserving their proliferative potential. This is in contrast to what is seen at ambient $20 \%$ oxygen tension, which is associated with cellular senescence and a more actively cycling cell population.

There have been studies demonstrating that an increase in ROS levels hampered the cell cycle quiescence in a hematopoietic stem cell system [Ito et al., 2006] and induced premature senescence [Welford et al., 2006]. Thus, the minimal production of ROS in hypoxic cells in contrast to its elevation in normoxic cells underpinned the data obtained in this study. This also contributed to the maintenance of an undifferentiated and quiescent state because mitochondrial ROS promote epithelial differentiation [Hamanaka et al., 2013]. Moreover, we detected that mTOR activity was downregulated in hypoxic cells, which is consistent with a previous report [Leontieva et al., 2012] and similar to our previous study using rapamycin, a potent mTOR inhibitor [Izumi et al., 2009]. The fact that mTOR activity was suppressed in basal cells of oral mucosa in vivo, as shown in our previous study, is indicative of a low physiological oxygen pressure in oral mucosa, as seen in skin [Rezvani et al., 2011a]. This suggests the energy production in basal cells is via anaerobic glycolysis rather than mitochondrial metabolism, which may be beneficial to minimize ROS production [Baris et al., 2011; Ivanovic et al., 2013].

Cellular adaptation and/or responses to a hypoxic microenvironment has been shown to be mediated by induction of the transcription factor HIF-1 $\alpha$ expression [Semenza, 2012; Moniz et al., 2014] that was confirmed in oral keratinocytes under 2 and $0.5 \%$ oxygen tensions in this study. Although the cellular responses shown in this study are likely to be attributed to the HIF-1a stabilization, further studies on HIF-1 $\alpha$-dependent and HIF$1 \alpha$-independent molecular mechanisms are necessary to elucidate how it regulates quiescence and an undifferentiated state of oral keratinocytes.
Our ultimate goal is to manufacture tissue-engineered oral mucosa grafts that are more consistent by manipulating culture conditions and improving the current clinical protocol [Izumi et al., 2013]. Clarification is needed to address the role of hypoxia in modulating the long-term proliferating potential and a regenerative capability of oral keratinocytes in vitro. It was recently shown that short-term hypoxic preconditioning of cells can enhance the angiogenic capacity of tissue-engineered oral mucosa [Perez-Amodio et al., 2011]. The ex vivo expansion of oral keratinocytes and manufacturing of tissue-engineered oral mucosa substitutes by manipulating oxygen tensions can be beneficial to strategies on the fabrication of cell-based products in regenerative medicine, eventually leading to the identification of an oralkeratinocyte stem cell and associated niche [Hawkins et al., 2013].

\section{Disclosure Statement}

The authors declare no conflicts of interest.

\section{Acknowledgement}

We thank Dr. Cynthia L. Marcelo and Dr. Toshiaki Tanaka for their critical comments, Dr. Masataka Oda for his technical assistance and Dr. Takeyasu Maeda for financial support of this study. This work was supported in part by a Grant-in-Aid for Scientific Research (No. 23659913 and 26293420) to K.I. from the Japan Society for the Promotion of Science (JSPS), and a National Institutes of Dental and Craniofacial Research Grant (No. R01 DE019431) to S.E.F.

References Baris, O.R., A. Klose, J.E. Kloepper, D. Weiland, J.F. Neuhaus, J. Schauen, et al. (2011) The mitochondrial electron transport chain is dispensable for proliferation and differentiation of epidermal progenitor cells. Stem Cells 29: 1459-1468.

Bath, C., S. Yang, D. Muttuvelu, T. Fink, J. Emmersen, H. Vorum, J. Hjortdal, V. Zachar (2013) Hypoxia is a key regulator of limbal epithelial stem cell growth and differentiation. Stem Cell Res 10: 349-360.

Blagosklonny, M.V. (2013) Hypoxia, MTOR and autophagy: converging on senescence or quiescence. Autophagy 9: 260-262.

Buravkova, L.B., Y.V. Rylova, E.R. Andreeva, A.V. Kulikov, M.V. Pogodina, B. Zhivotovsky, et al. (2013) Low ATP level is sufficient to maintain the uncommitted state of multipotent mesenchymal stem cells. Biochim Biophys Acta 1830: 4418-4425. 
Carreau, A., B. El Hafny-Rahbi, A. Matejuk, C. Grillon, C. Kieda (2011) Why is the partial oxygen pressure of human tissues a crucial parameter? Small molecules and hypoxia. J Cell Mol Med 15: 1239-1253.

-Chadli, L., E. Cadio, P. Vaigot, M.T. Martin, N.O. Fortunel (2013) Monitoring the cycling activity of cultured human keratinocytes using a CFSE-based dye tracking approach. Methods Mol Biol 989: 83-97.

Chandler, H., G. Peters (2013) Stressing the cell cycle in senescence and aging. Curr Opin Cell Biol 25: 765-771.

Chen, L., P.K. Gajendrareddy, L.A. DiPietro (2012) Differential expression of HIF-1a in skin and mucosal wounds. J Dent Res 91: 871876.

Cheung, T.H., T.A. Rando (2013) Molecular regulation of stem cell quiescence. Nat Rev Mol Cell Biol 14: 329-340.

Deschepper, M., K. Oudina, B. David, V. Myrtil, C. Collet, M. Bensidhoum, et al. (2011) Survival and function of mesenchymal stem cells (MSCs) depend on glucose to overcome exposure to long-term, severe and continuous hypoxia. J Cell Mol Med 15: 1505-1514.

-Genovese, C., D. Trani, M. Caputi, P.P. Claudio (2006) Cell cycle control and beyond: emerging roles for the retinoblastoma gene family. Oncogene 25: 5201-5209.

-Gérard, C., A. Goldbeter (2014) The balance between cell cycle arrest and cell proliferation: control by the extracellular matrix and by contact inhibition. Interface Focus 4: 20130075

Grayson, W.L., F. Zhao, B. Bunnell, T. Ma (2007) Hypoxia enhances proliferation and tissue formation of human mesenchymal stem cells. Biochem Biophys Res Commun 358: 948-953.

-Hamanaka, R.B., A. Glasauer, P. Hoover, S. Yang, H. Blatt, A.R. Mullen, et al. (2013) Mitochondrial reactive oxygen species promote epidermal differentiation and hair follicle development. Sci Signal 6: ra8.

-Haque, N., M.T. Rahman, N.H. Abu Kasim, A.M. Alabsi (2013) Hypoxic culture conditions as a solution for mesenchymal stem cell based regenerative therapy. ScientificWorldJournal 2013: 632972.

-Hawkins, K.E., T.V. Sharp, T.R. McKay (2013) The role of hypoxia in stem cell potency and differentiation. Regen Med 8: 771-782.

Helmbold, H., U. Galderisi, W. Bohn (2012) The switch from pRb/p105 to Rb2/p130 in DNA damage and cellular senescence. J Cell Physiol 227: 508-513.

Inatomi, T., T. Nakamura, M. Kojyo, N. Koizumi, C. Sotozono, S. Kinoshita (2006) Ocular surface reconstruction with combination of cultivated autologous oral mucosal epithelial transplantation and penetrating keratoplasty. Am J Ophthalmol 142: 757-764.

-Ito, K., A. Hirao, F. Arai, K. Takubo, S. Matsuoka, K. Miyamoto, et al. (2006) Reactive oxygen species act through 38 MAPK to limit the lifespan of hematopoietic stem cells. Nat Med 12: 446-451.
Ivanovic, Z. (2013) Respect the anaerobic nature of stem cells to exploit their potential in regenerative medicine. Regen Med 8: 677-680.

Izumi, K., K. Inoki, Y. Fujimori, C.L. Marcelo, S.E. Feinberg (2009) Pharmacological retention of oral mucosa progenitor/stem cells. J Dent Res 88: 1113-1118.

Izumi, K., R.F. Neiva, S.E. Feinberg (2013) Intraoral grafting of tissue-engineered human oral mucosa. Int J Oral Maxillofac Implants 28: e295-e303.

Izumi, K., T. Tobita, S.E. Feinberg (2007) Isolation of human oral keratinocyte progenitor/ stem cells. J Dent Res 86: 341-346.

Jung, Y.S., Y. Qian, X. Chen (2010) Examination of the expanding pathways for the regulation of p21 expression and activity. Cell Signal 22: 1003-1012.

Kato, H., K. Izumi, T. Saito, H. Ohnuki, M. Terada, Y. Kawano, et al. (2013) Distinct expression patterns and roles of aldehyde dehydrogenases in normal oral mucosa keratinocytes: differential inhibitory effects of a pharmacological inhibitor and RNAi-mediated knockdown on cellular phenotype and epithelial morphology. Histochem Cell Biol 139: 847-862.

Kim, J., K.E. Andersson, J.D. Jackson, S.J. Lee, A. Atala, J.J. Yoo (2014) Downregulation of metabolic activity increases cell survival under hypoxic conditions: potential applications for tissue engineering. Tissue Eng Part A 20: 2265-2272.

Kirschner, M., A. Montazem, H.S. Hilaire, A. Radu (2006) Long-term culture of human gingival keratinocyte progenitor cells by down-regulation of 14-3-3 $\sigma$. Stem Cells Dev 15: 556-565.

Leontieva, O.V., V. Natarajan, Z.N. Demidenko, L.G. Burdelya, A.V. Gudkov, M.V. Blagosklonny (2012) Hypoxia suppresses conversion from proliferative arrest to cellular senescence. Proc Natl Acad Sci USA 109: 13314-13318.

Miyashita, H., K. Higa, N. Kato, T. Kawakita, S. Yoshida, K. Tsubota, et al. (2007) Hypoxia enhances the expansion of human limbal epithelial progenitor cells in vitro. Invest Ophthalmol Vis Sci 48: 3586-3593.

Mohyeldin, A., T. Garzón-Muvdi, A. QuiñonesHinojosa (2010) Oxygen in stem cell biology: a critical component of the stem cell niche. Cell Stem Cell 7: 150-161.

Moniz, S., J. Biddlestone, S. Rocha (2014) Grow 2 : the HIF system, energy homeostasis and the cell cycle. Histol Histopathol 29: 589-600.

-Nakamura, T., K. Endo, S. Kinoshita (2007) Identification of human oral keratinocyte stem/ progenitor cells by neurotrophin receptor p75 and the role of neurotrophin/p75 signaling. Stem Cells 25: 628-638.

Ngo, M.A., N.N. Sinitsyna, Q. Qin, R.H. Rice (2007) Oxygen-dependent differentiation of human keratinocytes. J Invest Dermatol 127: 354-361.

O'Callaghan, A.R., J.T. Daniels, C. Mason (2011) Effect of sub-atmospheric oxygen on the culture of rabbit limbal epithelial cells. Curr Eye Res 36: 691-698.
Overton, K.W., S.L. Spencer, W.L. Noderer, T. Meyer, C.L. Wang (2014) Basal p21 controls population heterogeneity in cycling and quiescent cell cycle state. Proc Natl Acad Sci USA 111: E4386-E4393.

Perez-Amodio, S., W.M. Tra, H.A. Rakhorst, S.E. Hovius, J.W. van Neck (2011) Hypoxia preconditioning of tissue-engineered mucosa enhances its angiogenic capacity in vitro. Tissue Eng Part A 17: 1583-1593.

Rezvani, H.R., N. Ali, L.J. Nissen, G. Harfouche, H. de Verneuil, A. Taïeb, et al. (2011a) HIF-1a in epidermis: oxygen sensing, cutaneous angiogenesis, cancer, and non-cancer disorders. Invest Dermatol 131: 1793-1805.

Rezvani, H.R., N. Ali, M. Serrano-Sanchez, P. Dubus, C. Varon, C. Ged, et al. (2011b) Loss of epidermal hypoxia-inducible factor- $1 \alpha$ accelerates epidermal aging and affects re-epithelialization in human and mouse. J Cell Sci 124: 4172-4183.

Santilli, G., G. Lamorte, L. Carlessi, D. Ferrari, L. Rota Nodari, E. Binda, et al. (2010) Mild hypoxia enhances proliferation and multipotency of human neural stem cells. PLoS One 5: e8575.

-Semenza, G.L. (2012) Hypoxia-inducible factors in physiology and medicine. Cell 148: 399-408.

Thorn, J.J., F. Kallehave, P. Westergaard, E.H. Hansen, F. Gottrup (1997) The effect of hyperbaric oxygen on irradiated oral tissues: transmucosal oxygen tension measurements. J Oral Maxillofac Surg 55: 1103-1107.

Topley, G.I., R. Okuyama, J.G. Gonzales, C. Conti, G.P. Dotto (1999) p21 $1^{\mathrm{WAF} 1 / \mathrm{Cip} 1}$ functions as a suppressor of malignant skin tumor formation and a determinant of keratinocyte stemcell potential. Proc Natl Acad Sci USA 96: 9089-9094.

Vaapil, M., K. Helczynska, R. Villadsen, O.W. Petersen, E. Johansson, S. Beckman, et al. (2012) Hypoxic conditions induce a cancer-like phenotype in human breast epithelial cells. PLoS One 7: e46543.

Vanderkooi, J.M., M. Erecińska, I.A. Silver (1991) Oxygen in mammalian tissue: methods of measurement and affinities of various reactions. Am J Physiol 260: C1131-C1150.

Weinberg, W.C., M.F. Denning (2002) P21 WAF1 control of epithelial cell cycle and cell fate. Crit Rev Oral Biol Med 13: 453-464.

-Welford, S.M., B. Bedogni, K. Gradin, L. Poellinger, M. Broome Powell, A.J. Giaccia (2006) HIF1a delays premature senescence through the activation of MIF. Genes Dev 20: 3366-3371.

$\checkmark$ Wen, W., J. Ding, W. Sun, K. Wu, B. Ning, W. Gong, et al. (2010) Suppression of cyclin D1 by hypoxia-inducible factor-1 via direct mechanism inhibits the proliferation and 5-fluorouracil-induced apoptosis of A549 cells. Cancer Res 70: 2010-2019.

Yamamoto, Y., M. Fujita, Y. Tanaka, I. Kojima, Y. Kanatani, M. Ishihara, et al. (2013) Low oxygen tension enhances proliferation and maintains stemness of adipose tissue-derived stromal cells. Biores Open Access 2: 199-205.

Yao, G. (2014) Modelling mammalian cellular quiescence. Interface Focus 4: 20130074. 